\title{
Pembuatan Karbon Aktif dari Hasil Pirolisis Ban Bekas
}

\section{Production of Activated Carbon from Waste Rubber Tyres Pyrolisis}

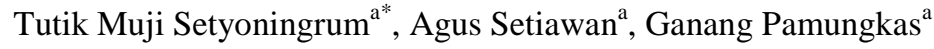 \\ ${ }^{a}$ Jurusan Teknik Kimia, Fakultas Teknik Industri, Universitas Pembangunan Nasional (UPN) “Veteran” Yogyakarta, Jalan \\ SWK 104 (Lingkar Utara), Condong Catur, Yogyakarta 55283 Indonesia
}

\section{Artikel histori : \\ Diterima 9 Oktober 2018 Diterima dalam revisi 15 Oktober 2018 Diterima 25 Oktober 2018 Online 31 Oktober 2018}

\begin{abstract}
ABSTRAK: Saat ini diperlukan alternatif energi baru terbarukan salah satunya minyak RCO (Rubber Compound Oil) yang dibuat dari bahan baku ban bekas. Pembuatan minyak RCO ini menimbulkan permasalahan berupa limbah karbon yang apabila dibuang akan menimbulkan dampak lingkungan. Diperlukan upaya untuk menangani limbah kabon hasil pirolisis ban bekas salah satunya adalah pembuatan karbon aktif guna meningkatkan nilai ekonomi limbah. Sehingga tujuan dari penelitian ini adalah untuk mempelajari kondisi operasi dalam pembuatan karbon aktif dari limbah hasil pyrolisis ban bekas. Karbon aktif merupakan salah satu adsorben yang dapat digunakan dalam pemurnian bahan. Penelitian ini membuat karbon aktif dengan menggunakan metode aktivasi kimia. $\mathrm{KOH}$ dipilih sebagai aktivating agent serta digunakan variabel suhu aktivasi dengan variasi suhu 700,800 , dan $900{ }^{\circ} \mathrm{C}$ dengan waktu aktivasi selama 30, 45, dan 60 menit. Pada penelitian ini diperoleh hasil karbon aktif terbaik dengan kondisi operasi $900{ }^{\circ} \mathrm{C}$ selama 60 menit yang menghasilkan luas permukaan karbon aktif seluas 230 $\mathrm{m}^{2} / \mathrm{g}$.
\end{abstract}

Kata Kunci: ban bekas, karbon aktif, aktivasi kimia

\begin{abstract}
Currently, alternative renewable energy is needed, one of which is RCO (Rubber Compound Oil) oil which is made from waste tires. The making of RCO oil causes problems in the form of carbon waste which, if discharged, will cause environmental impacts. Efforts are needed to deal with kabon waste resulting from used tire pyrolysis, one of which is the creation of activated carbon to increase the economic value of waste. So the purpose of this study is to study the operating conditions in the manufacture of activated carbon from waste produced by used tire pyrolysis. Activated carbon is one of the absorbents that can be used in material purification. This study makes activated carbon using a chemical activation method. $\mathrm{KOH}$ was chosen as activating agent and the activation temperature variable was used with temperature variations of 700,800 , and $900{ }^{\circ} \mathrm{C}$ with activation times for 30,45 , and 60 minutes. In this study, the best activated carbon was obtained with $900{ }^{\circ} \mathrm{C}$ operating conditions for 60 minutes which produced an active carbon surface area of $230 \mathrm{~m}^{2} / \mathrm{g}$.
\end{abstract}

Keywords: waste tyres, activated carbon, chemical activation

\section{Pendahuluan}

Indonesia adalah salah satu negara berkembang dengan jumlah pengguna kendaraan bermotor terbesar di dunia. Dengan bertambahnya pengguna kendaraan bermotor tentunya diiringi dengan meningkatnya produksi komponen dari kendaraan bermotor antara lain adalah ban. Ban menjadi salah satu komponen dari kendaraan bermotor yang dapat diganti setiap saat. Hal ini menimbulkan limbah berupa ban bekas.

Pirolisis merupakan peristiwa penguraian yang terjadi karena adanya panas. Oleh karena itu, keberadaan $\mathrm{O}_{2}$ yang dapat memicu reaksi pembakaran harus dihindari (Ismi Lufina, dkk, 2013)
Karbon aktif adalah padatan yang didominasi amorf yang memiliki luas permukaan internal dan volume pori yang besar. Karakteristik unik bertugas untuk penyerapan, yang dieksploitasi di berbagai aplikasi fase liquid dan gas. Karbon aktif adalah adsorben yang sangat serbaguna karena ukuran dan distribusi pori-pori dalam matriks karbon dapat dikendalikan untuk memenuhi kebutuhan saat ini dan pasar yang bermunculan (Kirk, 2004)

Aktivasi cara kimia pada prinsipnya adalah perendaman karbon dengan senyawa kimia sebelum dipanaskan. Pada proses pengaktifan secara kimia, karbon direndam dalam larutan pengaktifasi selama 24 jam, lalu ditiriskan dan dipanaskan pada suhu $600-900{ }^{\circ} \mathrm{C}$ selama 1 2 jam tanpa oksigen. Pada suhu tinggi bahan pengaktif akan masuk di antara sela-sela lapisan heksagonal dan

*Corresponding Author:

Email:tutikmuji@upnyk.ac.id 
selanjutnya membuka permukaan yang tertutup. Bahan kimia yang dapat digunakan yaitu $\mathrm{H}_{3} \mathrm{PO}_{4}, \mathrm{NH}_{4} \mathrm{Cl}, \mathrm{AlCl}_{3}$, $\mathrm{HNO}_{3}, \mathrm{KOH}, \mathrm{NaOH}, \mathrm{KMnO}_{4}, \mathrm{SO}_{3}, \mathrm{H}_{2} \mathrm{SO}_{4}$ dan $\mathrm{K}_{2} \mathrm{~S}$ (Kienle, 1986)

$$
\begin{aligned}
& \mathrm{KOH}+\mathrm{C}-\mathrm{O}-\mathrm{H} \leftrightharpoons \mathrm{C}-\mathrm{O}-\mathrm{K}+\mathrm{H}_{2} \mathrm{O} \\
& \mathrm{C}-\mathrm{O}-\mathrm{K}+\mathrm{K} \leftrightharpoons \mathrm{K}_{2} \mathrm{O}+\mathrm{C}
\end{aligned}
$$

$\mathrm{KOH}$ akan bereaksi dengan karbon sehingga akan membentuk pori-pori baru serta menghasilkan karbon dioksida yang berdifusi ke permukaan karbon (Pujiyanto, 2010). Pori-pori yang terbentuk akan menghasilkan karbon aktif. $\mathrm{KOH}$ juga mencegah pembentukan tar, asam asetat, metanol, dan lain lain (Atmayudha, 2006). Reaksi kimia yang terjadi sebagai berikut.

$$
\begin{aligned}
& 4 \mathrm{KOH}+\mathrm{C} \leftrightharpoons 4 \mathrm{~K}+\mathrm{CO}_{2}+2 \mathrm{H}_{2} \mathrm{O} \\
& 6 \mathrm{KOH}+2 \mathrm{C} \leftrightharpoons 2 \mathrm{~K}+3 \mathrm{H}_{2}+2 \mathrm{~K}_{2} \mathrm{CO}_{3} \\
& 4 \mathrm{KOH}+2 \mathrm{CO}_{2} \leftrightharpoons 2 \mathrm{~K}_{2} \mathrm{CO}_{3}+2 \mathrm{H}_{2} \mathrm{O}
\end{aligned}
$$

(Sudibandriyo, 2008).

Senyawa potassium carbonate $\left(\mathrm{K}_{2} \mathrm{CO}_{3}\right)$ merupakan hasil dari adanya reaksi kimia antara aktifier dengan sampel karbon. Terbentuknya senyawa ini juga disebabkan oleh reaksi antara aktifier dengan gas $\mathrm{CO}_{2}$ yang didapat selama aktivasi kimia. Senyawa potassium carbonate merupakan senyawa yang tidak diharapkan untuk terbentuk dan seharusnya senyawa ini hilang saat dilakukan pencucian pada proses aktivasi kimia.
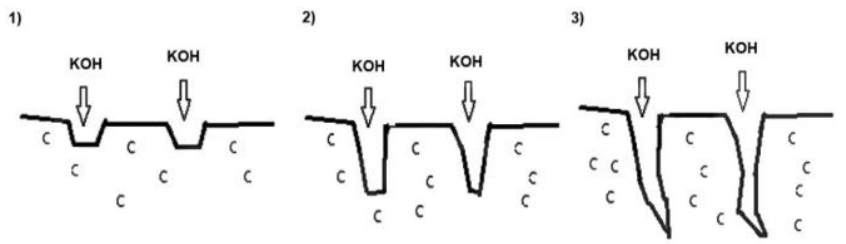

Gambar 1. Ilustrasi Pembentukan Pori Karbon Aktif Melalui Aktifasi $\mathrm{KOH}$

Menurut Standar Industri Indonesia (SII No. 0258-88) yang dikeluarkan oleh Departemen Perindustrian, persyaratan karbon aktif adalah sebagai berikut:

1. Bagian yang hilang pada suhu $950{ }^{\circ} \mathrm{C}=25 \%$

2. Air

$=15 \%$

3. Abu

$=10 \%$

4. Bagian yang tidak diperarang

5. Daya serap I2

$=$ tidak ada

$=\min .20 \%$

(LIPI, 1998/1999)

Dalam penelitian ini dibahas proses pembuatan karbon aktif dari hasil pirolisis ban bekas, pengaruh pemanasan terhadap luas permukaan karbon aktif serta memepelajari pengaruh lama waktu dan suhu pada proses aktivasi karbon aktif. Diharapkan proses pembuatan karbon aktif ini dapat mengatasi limbah karbon hasil pirolisis ban bekas.

\section{Metode Penelitian}

2.1 Alat

Alat yang digunakan dalam penelitian ini adalah grinder, furnace, oven, erlenmeyer, gelas beker, cawan, dan pengaduk.

\subsection{Bahan}

Bahan-bahan yang digunakan dalam penelitian ini adalah karbon hasil pyrolisis ban bekas dari PT. SS Energi, padatan $\mathrm{KOH}$, larutan $\mathrm{HCL} 5 \mathrm{~N}$, dan gas $\mathrm{N}_{2}$

\subsection{Cara Kerja}

Bahan baku karbon dihaluskan sampai ukuran $\pm 40-50$ mesh, kemudian dilarutkan dalam larutan $\mathrm{KOH}$ dengan perbandingan massa 3:1 terhadap massa karbon, campuran dipanaskan 2 jam pada suhu $200^{\circ} \mathrm{C}$. Selanjutnya sampel dimasukan ke dalam furnace dan dilakukan pemanasan dengan mengalirkan $\mathrm{N}_{2}$. Proses pemanasan dilakukan dengan variasi suhu $700,800,900{ }^{\circ} \mathrm{C}$, dan variasi waktu 30, 45, 60 menit. Selanjutnya sampel dicuci dengan larutan $\mathrm{HCl}$ dan aquades.

Sampel dikeringkan dengan oven sampai berat konstan lalu dianalisis luas permukaan dengan metode BET (Brunauer, Emmett and Taller),dengan alat BET NOVA 4200e, uji penyerapan iodine dengan metode titrasi, kadar air, dan kadar abu dengan menggunakan metode analisis

\begin{tabular}{|c|c|c|c|}
\hline Parameter & Unit & $\begin{array}{l}\text { Present } \\
\text { ase }(\%)\end{array}$ & Method \\
\hline $\begin{array}{l}\text { Mouisture in } \\
\text { Analysis }\end{array}$ & $\%, \mathrm{adb}$ & 1,1 & $\begin{array}{l}\text { ASTM } \\
3173-11\end{array}$ \\
\hline Ash Content & $\%, a d b$ & 11,8 & $\begin{array}{l}\text { ASTM } \\
3174-12\end{array}$ \\
\hline Volatile Matter & $\%$, adb & 7,6 & ISO $562-201$ \\
\hline Fix Carbon & $\%, \mathrm{adb}$ & 79,5 & $\begin{array}{l}\text { ASTM } \\
3172-13\end{array}$ \\
\hline Sulfur & $\%$, adb & 3,56 & $\begin{array}{l}\text { ASTM } \\
4239-14\end{array}$ \\
\hline Density & $\mathrm{g} / \mathrm{cc}$ & 0,654 & $\begin{array}{l}\text { ASTM } \\
291-12\end{array}$ \\
\hline
\end{tabular}
gravimetri.

\section{Hasil dan Pembahasan}

\subsection{Analisis Bahan Baku}

Tabel 1. Data Analisis Proximat Bahan Baku Karbon

Luas permukaan uji BET $=32,613 \mathrm{~m}^{2} / \mathrm{g}$

Berdasarkan data hasil analisis bahan baku diperoleh nilai kandungan fix carbon yang masih besar sehingga dapat dimanfaatkan sebagai bahan baku pembuatan karbon aktif. Dari hasil analisis luas permukaan bahan baku masih dapat dimungkinkan untuk bertambahnya luas permukaan karbon aktif hasil. 


\subsection{Yield karbon aktif hasil}

Terdapat pengurangan massa saat pencucian dan pengeringan, hal ini dikarenakan hilangnya senyawa sisasisa $-\mathrm{OH}$ dan zat-zat hasil reaksinya. Berikut ini tabel menunjukan perubahan massa yang terjadi setelah pencucian dan pengeringan karbon aktif.

Tabel 2. Yield karbon aktif hasil

\begin{tabular}{ccccc}
\hline $\mathrm{T}$ & $\mathrm{t}$ & $\begin{array}{c}\text { Massa } \\
\text { sebelum }\end{array}$ & $\begin{array}{c}\text { Massa } \\
\text { Karbon }\end{array}$ & $\begin{array}{c}\text { Yield } \\
\text { Karbon }\end{array}$ \\
$\begin{array}{c}\text { Aktivasi } \\
\left({ }^{\circ} \mathrm{C}\right)\end{array}$ & $\begin{array}{c}\text { Aktivasi } \\
(\text { menit })\end{array}$ & $\begin{array}{c}\text { Aktivasi } \\
(\text { gram })\end{array}$ & $\begin{array}{c}\text { Aktif } \\
(\text { gram })\end{array}$ & $\begin{array}{c}\text { Aktif } \\
(\%)\end{array}$ \\
\hline \multirow{2}{*}{700} & 30 & 30,0033 & 27,7754 & 92,57 \\
& 45 & 30,0176 & 27,3233 & 91,02 \\
& 60 & 30,0075 & 26,0308 & 86,75 \\
800 & 30 & 30,0032 & 25,9680 & 86,55 \\
& 45 & 30,0056 & 24,3400 & 81,12 \\
& 60 & 30,0165 & 23,8750 & 79,54 \\
& 30 & 30,0088 & 23,1034 & 76,99 \\
& 45 & 30,0021 & 21,6805 & 72,26 \\
& 60 & 30,0012 & 18,8064 & 62,69 \\
\hline
\end{tabular}

Dari hasil pencucian dan mengeringan dapat dilihat bahwa semakin tinggi suhu aktivasi, yield karbon aktif yang didapat semakin rendah. Hal ini terjadi karena semakin besar suhu aktivasi dan semakin lama waktu aktivasi, maka semakin banyak karbon yang terkikis dan bereaksi dnegan activating agent sehingga hasil reaksi karbon dengan $\mathrm{KOH}$ semakin banyak yeng keluar bersama dengan air cucian.

\subsection{Kadar Air Karbon Aktif}

Penentuan kadar air bertujuan untuk mengetahui sifat higroskopis dari karbon aktif yang dihasilkan,

Karbon aktif memenuhi SII No. 0258-88 yaitu kadar air maksimal 4,4\%. Namun pada suhu aktivasi $900{ }^{\circ} \mathrm{C}$ dengan waktu aktivasi 60 menit menunjukan hasil kadar air sebesar $4,7570 \%$.

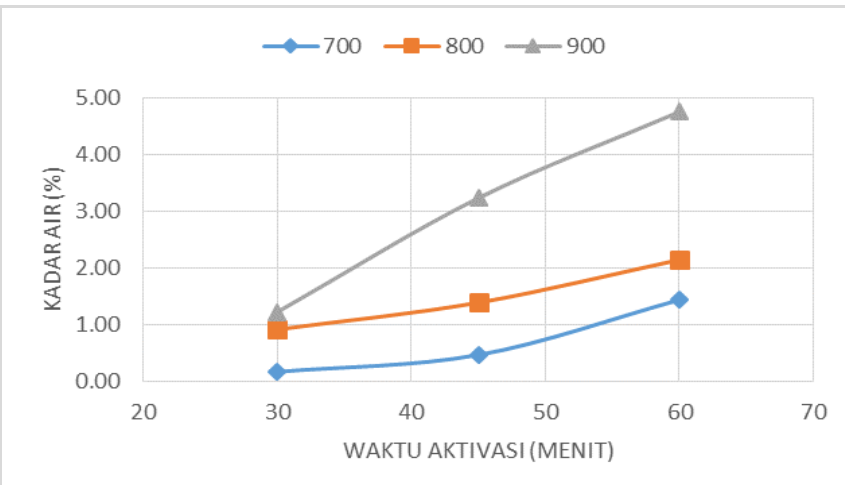

Gambar 2. Pengaruh suhu dan waktu aktivasi terhadap kadar air
Untuk mengetahui hubungan suhu dan waktu aktivasi dari hasil penelitian dapat dilihat pada Gambar 2 pada suhu 700, 800, dan $900^{\circ} \mathrm{C}$ kadar air karbon aktif semakin meningkat dengan bertambahnya waktu aktivasi. Menurut Kurniadi (2009), hal ini dikarenakan semakin lama waktu aktivasi, maka semakin banyak zat pengotor yang larut, sehingga semakin banyak pori-pori yang terbuka, dan pada saat pencucian karbon aktif, air masuk mengisi pori-pori lebih banyak. Hal ini dapat terjadi karena semakin banyaknya $\mathrm{KOH}$ yang bereaksi dengan bahan baku. Diperlukan analisis lebih lanjut menggunakan analisis FTIR untuk mengetahui banyaknya gugus fungsi dalam karbon aktif yang dapat mengiikat air. Sehingga dalam penggunaannya diperlukan usaha untuk mengurangi kadar air sebelum digunakan sebagai adsorben.

\subsection{Kadar Abu Karbon Aktif}

Kadar abu sangat berpengaruh pada kualitas karbon aktif yang dihasilkan. Kadar abu yang berlebihan dapat menyebabkan terjadinya penyumbatan pada pori-pori karbon aktif. Penentuan kadar abu bertujuan untuk menentukan kandungan oksida logam dalam arang. Berikut ditampilkan hasil analisis kadar abu karbon aktif.

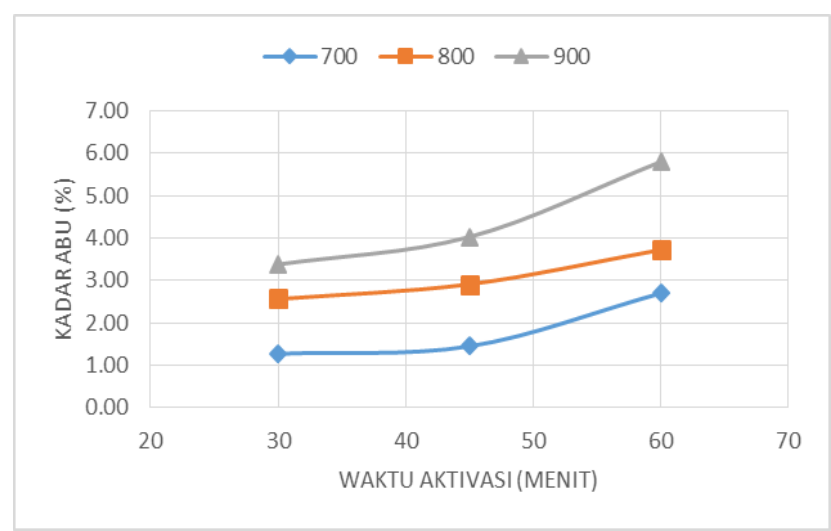

Gambar 3. Pengaruh suhu dan waktu aktivasi terhadap

\section{kadar abu}

Kadar abu yang dihasilkan berkisar antara 1,27 - 5,8 \%, sebagian karbon aktif yang dihasilkan memenuhi SII No. 0258-88. Yaitu maksimal 2,5\%. Karbon aktif yang memenuhi SNI yaitu karbon aktif dengan suhu aktivasi $700^{\circ} \mathrm{C}$ dengan waktu aktivasi 30 dan 45 menit. Selain itu karbon aktif tidak memenuhi SII No. 0258-88. Tingginya kadar abu didalam karbon aktif hasil disebabkan oleh bahan baku karbon yang digunakan yaitu berasal dari hasil pyrolysis ban bekas yang terjadi pada suhu yang tinggi dan waktu pyrolysis yang lama melewati temperature karbonisasi karbon hitam. Hal ini ditunjukkan oleh hasil analisis kadar abu dalam bahan sebesar 11,8\%.

\subsection{Uji Penyerapan Iodine}

Penentuan daya serap iodine bertujuan untuk menentukan kapasitas adsorpsi karbon aktif. Daya serap karbon aktif terhadap iodine memiliki hubungan dengan luas permukaan dari karbon aktif. Semakin besar angka iodine maka 
semakin besar kemampuan karbon aktif dalam menyerap adsorbat atau zat terlarut. Berikut ditampilkan hasil analisis uji penyerapan iodine.

Hanya sebagian kecil saja hasil karbon aktif yang memenuhi SII No. 0258-88 yaitu minimal $750 \mathrm{mg} / \mathrm{g}$, dari ke sembilan karbon aktif hanya tiga yang memenuhinya. Yaitu pada suhu aktifasi $800^{\circ} \mathrm{C}$ dengan waktu 60 menit, dan suhu $900^{\circ} \mathrm{C}$ dengan waktu aktivasi 45 , dan 60 menit. Masing-masing dengan angka iodine 785,37; 904,37; $975,77 \mathrm{mg} / \mathrm{g}$.

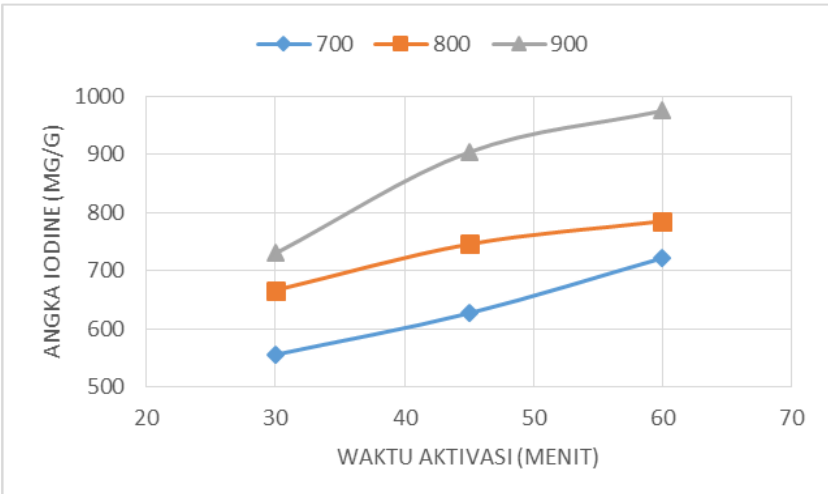

Gambar 4. Pengaruh suhu dan waktu aktivasi terhadap angka iodine

Dari hasil yang didapat dapat dilihat pada Gambar 4, pada suhu 700, 800 dan $900{ }^{\circ} \mathrm{C}$, semakin lama waktu aktivasi karbon, hasil yang didapat angka iodine semakin meningkat. Kenaikan suhu juga berpengaruh terhadap angka iodine, semakin tinggi suhu aktivasi, angka iodine yang didapat semakin meningkat. Hal ini dapat dilihat pada waktu aktivasi 30, 45, dan 60 menit. Peningkatan bilangan iodine menunjukan semakin banyaknya pengotor yang terlepas dari karbon aktif pada saat aktivasi. Selama peningkatan suhu dan waktu aktivasi, pengotor-pengotor yang menutupi pori karbon aktif akan terlepas atau teruapkan sehingga luas permukaan karbon aktif akan meningkat.

\subsection{Karakterisai Luas Permukaan Karbon Aktif}

Karbon aktif dengan luas permukaan yang tinggi merupakan adsorben yang potensial untuk penggunaanya pada proses adsorpsi. Metode pengukuran luas permukaan ini diukur dengan metode BET.

Untuk mengetahui pengaruh suhu dan waktu aktivasi terhadap luas permukaan dapat dilihat di gambar 5. Suhu aktivasi mempengaruhi luas permukaan karbon yang dihasilkan, semakin meningkatnya suhu aktivasi maka luas permukaan yang dihasilkan akan semakin tinggi. Hal ini dikarenakan pada suhu yang lebih tinggi partikel $\mathrm{KOH}$ akan lebih aktif untuk membuka pori baru di dalam karbon aktif.

Waktu aktivasi juga mempengaruhi luas permukaan karbon yang dihasilkan, semakin lama waktu aktivasi maka luas permukaan yang dihasilkan semakin besar. Luas permukaan tertinggi yang dihasilkan adalah pada karbon yang diaktivasi pada suhu $900^{\circ} \mathrm{C}$ dengan waktu 60 menit yaitu sebesar 230,654 $\mathrm{m}^{2} / \mathrm{g}$. Hal ini menunjukkan peningkatan jika dibandingkan dengan luas permukaan karbon bahan baku yaitu $32,613 \mathrm{~m}^{2} / \mathrm{g}$.

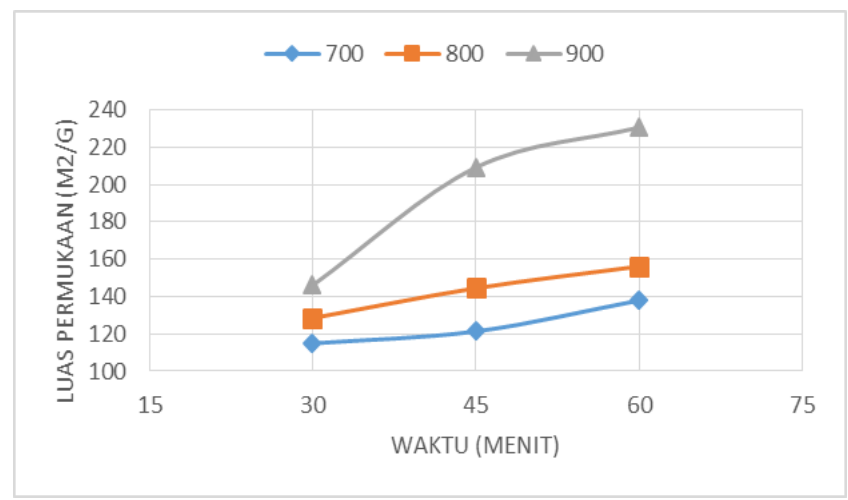

Gambar 5. Pengaruh suhu dan waktu terhadap luas permukaan

Berdasarkan data hasil analisis yang dilakukan terhadap karbon aktif yang telah dihasilkan menunjukan bahwa belum tercapainya kondisi optimum pembuatan karbon aktif dari hasil pirolisis ban bekas. Kondisi optimum akan tercapai pada suhu dan lama waktu aktivasi diatas dari variabel penelitian yang digunakan hingga tercapainya crashing point di mana pada suhu dan waktu operasi tertentu luas permukaan akan berkurang sebagai indikasi rusaknya karbon aktif akibat suhu dan waktu aktivasi yang melebihi kondisi optimum.

\section{Kesimpulan}

Dari hasil penelitian ini dapat disimpukan, Karbon dari hasil pirolisis ban bekas dapat dibuat menjadi karbon aktif. Semakin tinggi suhu dan lama waktu aktivasi luas permukaan yang didapat semakin besar, kadar air semakin tinggi, kadar abu semakin tinggi, dan angka iodine semakin tinggi. Karbon aktif dengan luas permukaan tertinggi sebesar $230 \mathrm{~m}^{2} / \mathrm{g}$. Hasil ini didapat dari karbon aktif dengan suhu aktifasi $900^{\circ} \mathrm{C}$ dengan waktu aktivasi 60 menit.

\section{Daftar Pustaka}

Arita, Assalami A, Dina W, 2015. Proses Pembuatan Bahan Bakar Cair dengan Memanfaatkan Limbah Ban Bekas Menggunakan Katalis Zeolit. Jurnal Teknk Kimia. Universitas Sriwijaya, Palembang.

Atmayudha, A (2007). Pembuatan Karbon Aktif Berbahan Dasar Tempurung Kelapa dengan Perlakuan aktivasi Terkontrol serta Uji Kinerjanya, Skripsi, Departemen Teknik Kima FTUI.

Cheremisinoff, P.N., 1978, Carbon Adsorption Handbook, Ann Arbor Science PublInc, Michigan.

Damayanthi, Reska., dan Martini, Retno. 2009. Proses Pembuatan Bahan Bakar Cair dengan Memanfaatkan Limbah Ban Bekas menggunakan Katalis 
Elly Kurniati, 2008. Pemanfaatan Cangkang Kelapa Sawit Sebagai Arang Aktif. Penelitian, Jurusan Teknik Kimia FTI UPN "Veteran" Jawa Timur.

Fuadi Ramdja, Mirah H, Jo Handi, 2008. Pembuatan Karbon Aktif Dari Pelepah Kelapa (Cocus nucifera). Juranal Teknik Kimia Fakultas Teknik Universitas Sriwijaya, Sumatra Seltan.

Jamilatun Siti, Martomo Setyawan, 2014. Pembuatan Arang Aktif dari Temputrung Kelapa dan Aplikasinya untuk Penjernihan Asap Cair. Jurnal Jurusan Teknik Kimia Fakultas Teknologi Industri Universitas Ahmad Dahlan, Yogyakarta

Jankowska.H, Swiatkowski.A and Choma.J, 1991, Active Carbon, Ellis Horwood

Limited, England.

Kirk, R,E and Othemar, D.F. 1978. Encyclopedia of Chemical Technology. Vol 5. Interscience Encyclopedia. Inc, New York.

Lufina, Ismi., Bambang, Susilo., \& Rini, Yulianingsih. (2013). Studi Pemanfaatan Minyak Karet (Havea brasiliensis) sebagai Bahan Bakar pada Kompor Rumah Tangga. Jurnal Keteknikan Pertanian Universitas Brawijaya, Malang.

Manocha, S.M, 2003. Porous Carbons. Sadhana 28:335348

Maulana Andri. 2011, Pembuatan Karbon Aktif Berbahan Dasar Petroleum Coke dengan Metode Aktivasi Kimiawi. Skripsi Departemen Teknik Kimia, FTUI.

Meilita Taryana, 2002, Arang Aktif (Pengenalan dan Proses Pembuatannya), Skripsi Jurusan Teknik Industri Fakultas Teknik Sumatra Utara.
Murti, S.2008, Skripsi: Pembuatan Karbon Aktif dari Tongkol Jagung untuk Adsorpsi Molekul Amonia dan Ion Krom.Depok: Universitas Indonesia

Prabowo, A.L, 2009.Skripsi: Pembuatan Karbon Aktif dari Tongkol Jagung serta Aplikasinya untuk Adsorpsi $\mathrm{Cu}$, $\mathrm{Pb}$, dan Amonia. Depok: Universitas Indonesia

Pujiyanto. 2010. Pembuatan Karbon Aktif Super dari Batubara dan Tempurung Kelapa. Skripsi, Depok, Departemen Teknik Kimia Fakultas Teknik Universitas Indonesia.

Sembiring, Meilita Tryana. Sinaga, Tuti Sarma. 2003. Arang Aktif (Pengenalan dan Proses Pembuatanya). Sumatera Utara: Jurusan Teknik Industri Universitas Sumatera Utara.

Shofa. 2012, Skripsi: Pembuatan Karbon Aktif Berbahan Baku Ampas Tebu Dengan Aktivasi Kalium Hidroksida. Depok: Universitas Indonesia.

Sudibandriyo, M. 2003 A Generalized Ono-Kondo Lattice Model For High Pressure on Carbon Adsorben, Ph.D Dissetation. Oklahoma State University

Sudrajat, R., Pari, G. 2011. Arang Aktif Teknologi Pengolahan dan Masa Depanya. Badan penelitian dan Pengembangn Kehutanan dan Kementrian Kehutanan.

Teng, H., Hsu, L.Y. 2000 Influence of different chemical reagent on the preparation of activated carbons from bituminous coal. Fuel Processing Technology, 64, 155166.

PT. Sukses Sejahtera Energi. 2016. Report Of Analysis Carbon Black, Karanganyar. 